\title{
Exploring Eimeria Genomes to Understand Population Biology: Recent Progress and Future Opportunities
}

\author{
Damer P. Blake ${ }^{1, *(\mathbb{D})}$, Kate Worthing ${ }^{2}$ and Mark C. Jenkins ${ }^{2}$ \\ 1 Pathobiology and Population Sciences, Royal Veterinary College, Hawkshead Lane, \\ North Mymms AL9 7TA, UK \\ 2 Animal Parasitic Diseases Laboratory, Building 1040, Agricultural Research Service, USDA, \\ Beltsville, MD 20705, USA; kate.worthing@usda.gov (K.W.); mark.jenkins@usda.gov (M.C.J.) \\ * Correspondence: dblake@rvc.ac.uk
}

Received: 26 August 2020; Accepted: 18 September 2020; Published: 21 September 2020

\begin{abstract}
Eimeria, protozoan parasites from the phylum Apicomplexa, can cause the enteric disease coccidiosis in all farmed animals. Coccidiosis is commonly considered to be most significant in poultry; due in part to the vast number of chickens produced in the World each year, their short generation time, and the narrow profit margins associated with their production. Control of Eimeria has long been dominated by routine chemoprophylaxis, but has been supplemented or replaced by live parasite vaccination in a minority of production sectors. However, public and legislative demands for reduced drug use in food production is now driving dramatic change, replacing reliance on relatively indiscriminate anticoccidial drugs with vaccines that are Eimeria species-, and in some examples, strain-specific. Unfortunately, the consequences of deleterious selection on Eimeria population structure and genome evolution incurred by exposure to anticoccidial drugs or vaccines are unclear. Genome sequence assemblies were published in 2014 for all seven Eimeria species that infect chickens, stimulating the first population genetics studies for these economically important parasites. Here, we review current knowledge of eimerian genomes and highlight challenges posed by the discovery of new, genetically cryptic Eimeria operational taxonomic units (OTUs) circulating in chicken populations. As sequencing technologies evolve understanding of eimerian genomes will improve, with notable utility for studies of Eimeria biology, diversity and opportunities for control.
\end{abstract}

Keywords: Eimeria; genome; genetics; population structure; chickens

\section{Introduction}

Eimeria are protozoan parasites that generally invade and develop within epithelial cells of the intestinal tract. Although over 1500 species have been described that infect a wide range of vertebrate hosts including mammals, birds, fish, reptiles and amphibians [1], Eimeria are, with few exceptions, absolutely host-specific [2]. For instance, Eimeria falciformis will only infect mice and not rats, which can be parasitized by Eimeria nieschulzi [3]. Eimeria are members of a large group of protozoa that include the parasites Toxoplasma gondii and the Plasmodium species in the phylum Apicomplexa. Protozoa in this phylum share a conoid structure in the apical complex that plays a role in host cell invasion [4]. Eimeria and T. gondii are placed in the order Eucococcia, suborder Eimeriina. Although the term 'coccidiosis' can be used to describe any disease caused by coccidian parasites, it is generally used to refer to infection by Eimeria, and particularly those of poultry. Coccidiosis of chickens is a devastating intestinal disease that inflicts costs in excess of US\$ 13.6 billion/UK£ 10.4 billion on the global poultry production industry through the costs of control and losses in production, including egg layers, broilers reared for meat and breeding stock [5]. Avian coccidiosis has been, and commonly continues to be, controlled by routine medication of feed with ionophore drugs or synthetic chemicals. 
Alternative means of preventing coccidiosis, such as vaccination with low doses of either virulent or attenuated Eimeria oocysts, have gained favor for various reasons including repeated appearance of drug-resistance in response to continuous drug use and public demand for reduced drug use in food production [6]. Coccidiosis is often characterized by veterinarians as the most important disease of poultry because of morbidity and mortality associated with Eimeria infection [7]. Understanding the molecular epidemiology of coccidiosis is important if one is to protect the greater than 68 billion broiler and 7 billion egg layer chickens that are produced each year worldwide [8].

The disease coccidiosis can be said to begin after the invasion of epithelial cells by sporozoites that are released from sporocysts by the action of bile salts and enzymes, such as trypsin. Sporocysts themselves are contained within oocysts that have a wall composed of glycoprotein and lipid, which is broken down either by the grinding action of the ventriculus (gizzard) in avians or the effect of carbon dioxide and transit through the acidic environment of the stomach (non-avians) [9]. After host cell invasion, sporozoites initiate $2-4$ rounds of asexual replication termed schizogony, producing large numbers of merozoites that invade other cells leading to a subsequent round of schizogonous development or to sexual replication with the production of male and female gametes (microgamonts and macrogamonts). Microgamonts develop into microgametes that fertilize macrogametes to form zygotes, subsequently developing into oocysts. Aside from a diploid zygote stage, all other Eimeria developmental stages are haploid; a feature that is directly relevant to studies of Eimeria genomes and genetics $[10,11]$. Oocysts are generally released in feces and under the right conditions of temperature, humidity and oxygen content, undergo rounds of meiosis and mitosis (sporulation) to produce haploid sporozoites [12]. Oocysts are extremely resistant to a wide range of environmental conditions that are typically found in commercial broiler houses. In fact, studies have shown that Eimeria oocysts remain viable in litter for several weeks between different sets of broilers, infecting the next batch of chickens and thus perpetuating disease indefinitely [13,14]. Most Eimeria lifecycles are relatively quick compared to other apicomplexans, commonly represented by pre-patent periods shorter than one week [15], and lack long-term persistence within the host in the absence of an in vivo cyst phase, suggesting an "hit and run" lifecycle. However, it is notable that Eimeria species that infect migratory avian species such as crane (E. gruis and E. reichenowi) or corncrake (E. crecis and E. nenei) can cause longer lasting disseminated visceral coccidiosis $[16,17]$ and appear to be phylogenetically distinct from the more classical Eimeria species that infect mammals and non-migratory avians [18]. Wider sampling of Eimeria genomes will contribute to resolution of taxonomy within the genus and relationships with other closely related genera such as Cyclospora and Cystoisospora $[19,20]$.

There now is consensus that seven Eimeria species are capable of infecting the domestic chicken, Gallus gallus domesticus [21]. These seven species can be divided into two groups-those causing hemorrhagic disease (E. brunetti, E. necatrix, and E. tenella) and those primarily causing malabsorption (E. acervulina, E. maxima, E. mitis, and E. praecox) [10]. Of interest is that each of these seven Eimeria species has a predilection for a particular region of the chicken gut. For instance, E. acervulina is predominantly found in the duodenum, E. maxima in the jejunum and ileum, and E. tenella in the caeca [15]. Many species of Eimeria cannot reliably be differentiated by microscopy because of similar morphologies and overlapping sizes of the oocyst stage. Molecular techniques such as PCR have proven useful to distinguish different Eimeria species. Gene targets include ribosomal genes including the $18 \mathrm{~S}$ rDNA, internal transcriber spacer (ITS) sequences 1 and 2, as well as genes contained within the mitochondrial genome such as cytochrome c oxidase subunit I (COI) [22,23]. Molecular techniques have contributed to the resolution of taxonomic controversies such as the existence of $E$. mivati, where the identification of two different versions of the $18 \mathrm{~S}$ rDNA sequence in E. mitis, one of which was identical to that purported to be derived from E. mivati, proved to be decisive [21]. More intriguingly, others using PCR to amplify and sequence a fragment from the ITS2 region have provided evidence for the existence of three additional Eimeria 'genotypes', currently referred to as cryptic species or operational taxonomic units OTUx, OTUy, and OTUz [24,25]. Preliminary phylogenetic inference suggests that each cryptic Eimeria OTU is related to, but distinct from, recognized Eimeria species with 
close affinities to E. maxima, E. brunetti and E. mitis, respectively [26]. Until recently the cryptic OTU genotypes appeared to be geographically restricted, primarily within the southern hemisphere [25], although recent studies have suggested a wider spatial occurrence [27]. Attempts to resolve questions around the heritage of these and other OTU Eimeria genotypes will benefit from recent and future advances in genomics and genetics.

\section{Eimeria Genomes}

Eimerian genomes are thought to consist of a nuclear genome including 14 chromosomes of $1-7 \mathrm{Mb}[28,29]$, a mitochondrial genome of $\sim 6200 \mathrm{bp}$ [26] and an $\sim 35 \mathrm{~kb}$ circular apicoplast genome [30]. Additional double stranded RNA viral genomes have been described from many Eimeria species including E. brunetti, E. maxima, E. necatrix and E. tenella, representing a subgenus of the Totiviridae family recently proposed to be named Eimeriaviruses [31,32].

Karyotyping of Eimeria genomes lagged behind many other eukaryotes, in part because visualization and analysis of cell contents were hampered by the extreme mechanical resistance of the oocyst wall, the breakdown of which typically necessitated such mechanical force that cell contents were disrupted. Pulsed-field gel electrophoresis (PFGE) using chromosomal grade genomic DNA extracted from agarose preserved E. tenella sporozoites by Shirley [28] indicated that the organism had at least 14 chromosomes, ranging in size from 1 to $6-7 \mathrm{Mb}$; observations that were supported by linkage mapping [33] and later by del Cacho, Pages, Gallego, Monteagudo and Sánchez-Acedo [29] via electron microscopy. Del Cacho, et al. [34] developed a less vigorous method of cell wall breakdown using clorhidric (hydrochloric) acid-ethanol and freeze-thawing; this allowed the visualization of intact pachytene synaptonemal complexes during meiosis by transmission electron microscopy and identification of at least 14 chromosomes in E. tenella [29]. Interestingly, recent application of third generation Oxford Nanopore genome sequencing to the closely related coccidians Neospora caninum and T. gondii has reduced their karyotypes from 14 to 13 chromosomes [35,36]. Equivalent studies with Eimeria may be similarly informative.

All Eimeria genomes sequenced to date feature a segmented chromosome structure characterized by repeat-rich $(\mathrm{R})$ and repeat-poor $(\mathrm{P})$ regions $[10,37,38]$. The most common repeat sequence is the trinucleotide CAG, which is ubiquitous across the genome and common in protein-coding regions [10,37]. The CAG repeats result in stretches of homopolymeric amino acid repeats (HAARs) that are translated and transcribed, seemingly without affecting protein structure or function [10]. Other repeats such as the heptamer AAACCCT/AGGGTTT are also common, but not within coding sequences where they would disrupt coding frames, as are fragmented retrotransposon-like elements comparable to chromovirus long-terminal repeat (LTR) retrotransposons. High levels of sequence degeneracy suggest that these retrotransposons are unlikely to be functional, although the quality of the sequence assemblies have hindered analysis. While repeat types are well conserved in the sequenced Eimeria species, the frequency and location of repeats vary across species [10] and may also vary among strains within species [28]. Shirley [28] observed differing homologous chromosome sizes among different strains of E. tenella and postulated that variation in the number of CAG repeats may be one explanation for size variation between strains. No function has been assigned to these repeats and they have not been associated with specific genes or gene families, although it has been suggested that they might contribute to varied levels of recombination and genome evolution $[10,37]$.

To date, all publicly available Eimeria genome sequence assemblies exist as scaffolds made up of hundreds or even thousands of contigs or supercontigs (Table 1). The relatively short sequence reads produced by Sanger, Illumina and pyrosequencing have been unable to span many of the repeat-rich regions, precluding assembly to whole chromosome levels. Draft sequence assemblies have been published for all seven of the recognized Eimeria species that infect chickens, represented by up to three strains per species [10,39]. A genome sequence of the mouse-associated species E. falciformis was released in 2014 [38], followed by the brown rat-associated species E. nieschulzi as part of a gametocyte gene discovery project in 2017 [3]. No other Eimeria genome sequences have been published to date. 
Consideration of assembly quality, including the number of contigs and level of curation, led Reid and colleagues to identify three tiers. The E. tenella genome was considered to be tier 1 , representing the highest quality of assembly and annotation at the time of publication [10]. The E. falciformis assembly can also be considered to be tier 1. An intermediate grouping of E. acervulina, E. maxima and E. necatrix was included as tier 2, restricted to automatic post-assembly improvements only. The genome assemblies for E. mitis, E. necatrix, E. nieschulzi and E. praecox were least refined, described as or equivalent to tier 3. Recognizing the limitations of these resources, it is striking to note a 1.7-fold difference between the smallest (E. maxima, $42.5 \mathrm{Mb}$ ) and largest (E. mitis, $72.2 \mathrm{Mb}$; Table 1 ) assemblies. Comparison with the T. gondii genome annotation revealed that $93-99 \%$ of the core eukaryotic genes were detectable in the tier 1 and 2 Eimeria genomes. As has occurred with Toxoplasma gondii and Neospora caninum [35,36], the application of third generation sequencing technologies can be expected to provide a dramatic improvement in Eimeria genome sequence resources in the near future.

Table 1. A summary of genome sequence assemblies available for Eimeriidae family parasites. Data derived from ToxoDB ([40]; accessed on 14 July 2020) and references as cited.

\begin{tabular}{|c|c|c|c|c|c|}
\hline $\begin{array}{l}\text { Parasite } \\
\text { Species }\end{array}$ & Parasite Strain & $\begin{array}{l}\text { SequencinG } \\
\text { Platform }\end{array}$ & $\begin{array}{l}\text { Assembly Size } \\
(\mathrm{Mb})\end{array}$ & $\begin{array}{c}\text { No. } \\
\text { Contigs/Supercontigs }\end{array}$ & Reference \\
\hline E. acervulina & Houghton & $\begin{array}{l}\text { Illumina HiSeq } \\
2000\end{array}$ & 45.8 & 3415 & [10] \\
\hline E. brunetti & Houghton & $\begin{array}{l}\text { Illumina HiSeq } \\
2000\end{array}$ & 66.9 & 8575 & [10] \\
\hline \multirow[t]{2}{*}{ E. maxima } & Houghton & $\begin{array}{c}\text { Sanger } \\
\text { capillary and } \\
\text { Roche GS-FLX } \\
454\end{array}$ & 46.0 & 22,259 & [39] \\
\hline & Weybridge & $\begin{array}{l}\text { Illumina HiSeq } \\
2000\end{array}$ & 42.5 & 3564 & [10] \\
\hline E. mitis & Houghton & $\begin{array}{l}\text { Illumina HiSeq } \\
2000\end{array}$ & 72.2 & 15,978 & [10] \\
\hline E. necatrix & Houghton & $\begin{array}{l}\text { Illumina HiSeq } \\
2000\end{array}$ & 55.0 & 3707 & [10] \\
\hline E. praecox & Houghton & $\begin{array}{l}\text { Illumina HiSeq } \\
2000\end{array}$ & 60.1 & 21,348 & [10] \\
\hline \multirow[t]{3}{*}{ E. tenella } & Houghton & $\begin{array}{c}\text { Sanger } \\
\text { capillary and } \\
\text { Illumina GAIIx }\end{array}$ & 51.9 & 4664 & [10] \\
\hline & Nippon-2 & Illumina GAIIx & na & na & {$[10,41]$} \\
\hline & $\begin{array}{l}\text { Wisconsin } \\
\text { Bayer }\end{array}$ & Illumina GAIIx & na & na & {$[10,41]$} \\
\hline E. falciformis & $\begin{array}{l}\text { Haberkorn } \\
1970\end{array}$ & Illumina GAIIx & 43.7 & 753 & [38] \\
\hline E. nieschulzi & Landers & $\begin{array}{l}\text { Illumina HiSeq } \\
2000\end{array}$ & 63.0 & 33,467 & [3] \\
\hline \multirow[t]{2}{*}{ C. cayetanensis } & CHN_HEN01 & $\begin{array}{c}\text { Roche GS-FLX } \\
\text { 454, Illumina } \\
\text { GAIIx and } \\
\text { Illumina HiSeq } \\
2500\end{array}$ & 46.8 & 4811 & [19] \\
\hline & NF1_C8 & Illumina MiSeq & 44.4 & 738 & [42] \\
\hline
\end{tabular}

na $=$ not applicable (reads aligned against the E. tenella Houghton reference strain, not de novo assembled).

All Eimeria genomes sequenced to date have been found to contain two or more paralog clusters of genes that encode surface antigens (SAGs) [38]. Some E. tenella SAG proteins have been shown to bind mammalian cells [43] and/or induce inflammatory responses in avian macrophages [44]. A loose association has been suggested between SAG gene number and Eimeria species pathogenicity, where species and lifecycle stages that express more SAGs tend towards higher pathogenicity, although a functional link has not been proven [10]. Comparison of Eimeria species that infect mammalian or avian hosts suggest distinct clades of SAG genes, with one exception within the SAGa cluster. 
Protein structural analyses suggest that the equivalent srs surface antigen-coding genes within the T. gondii derive from a distinct evolutionary origin [10].

In addition to the nuclear genome, apicomplexans have an $\sim 35 \mathrm{~kb}$ circular molecule of extrachromosomal DNA located within an organelle termed the apicoplast [45,46]. Thought to have evolved via the symbiotic engulfment of an algal cell, the apicoplast contributes to key cellular functions such as fatty acid production and heme synthesis [47-49]. The genome of the E. tenella apicoplast was first sequenced by long range overlapping PCR, confirming a comparable gene set to those described for the T. gondii and Plasmodium falciparum apicoplast genomes [30], and later showing a high degree of similarity to the apicoplast genome of $C$. cayetanensis [50].

Complete mitochondrial genome sequences have also been published for all Eimeria species that infect chickens, as well as several species from turkeys and rabbits, supplemented by E. falciformis (mouse) and E. zuernii (cattle) [26,51,52]. Primarily used for phylogenetic inference, the mitochondrial genomes of Eimeria form concatemers of $\sim 6200 \mathrm{bp}$ (6148-6261 bp). The mitochondrial genome sequences contain more than $60 \%$ adenine and thymine nucleobases $(\mathrm{A}+\mathrm{T})$, and include the protein coding genes cytochrome $c$ oxidase subunits I (COI) and III (COIII), and cytochrome b (CytB). The mitochondrial genomes also encode ribosomal large and small subunit rRNA sequences.

\section{Comparative Genomics}

Coccidian parasites of the family Eimeriidae have traditionally been characterized by features such as sporulated oocyst morphology, including the number of sporocysts per oocyst, and the number of sporozoites per sporocyst [53]. Sporulated oocysts of Eimeria species can usually be differentiated from other coccidia by the presence of four sporocysts, each containing two sporozoites. Recent phylogenetic inference using apicoplast and mitochondrial genomes has revealed a close relatedness between the genus Eimeria and Cyclospora [50], with C. cayetanensis located within an eimerian clade (Figure 1). Such phylogenetic comparison has revealed the apparently paraphyletic nature of the genus, although markers such as COI have proven to be equivocal, especially when analysis is restricted to short fragments [54]. Sporulated Cyclospora oocysts differ from Eimeria, defined by two sporocysts rather than four, but Eimeria lines defined by a heritable bisporocytic oocyst appearance have been described following drug selection [55]. Comparative analysis of the C. cayetanensis and E. tenella genomes suggest that these parasites share common coccidia-like metabolism and invasion pathways, but present with distinct surface antigens, despite detection of a small number of putative Eimeria TA4-like SAG coding sequences in the $C$. cayetanensis genome [19]. The functional similarities between Eimeria and Cyclospora genomes indicate opportunities to use Eimeria as model organisms for human pathogens such as $C$. cayetanensis that cannot currently be cultured in vitro or ex vivo. 


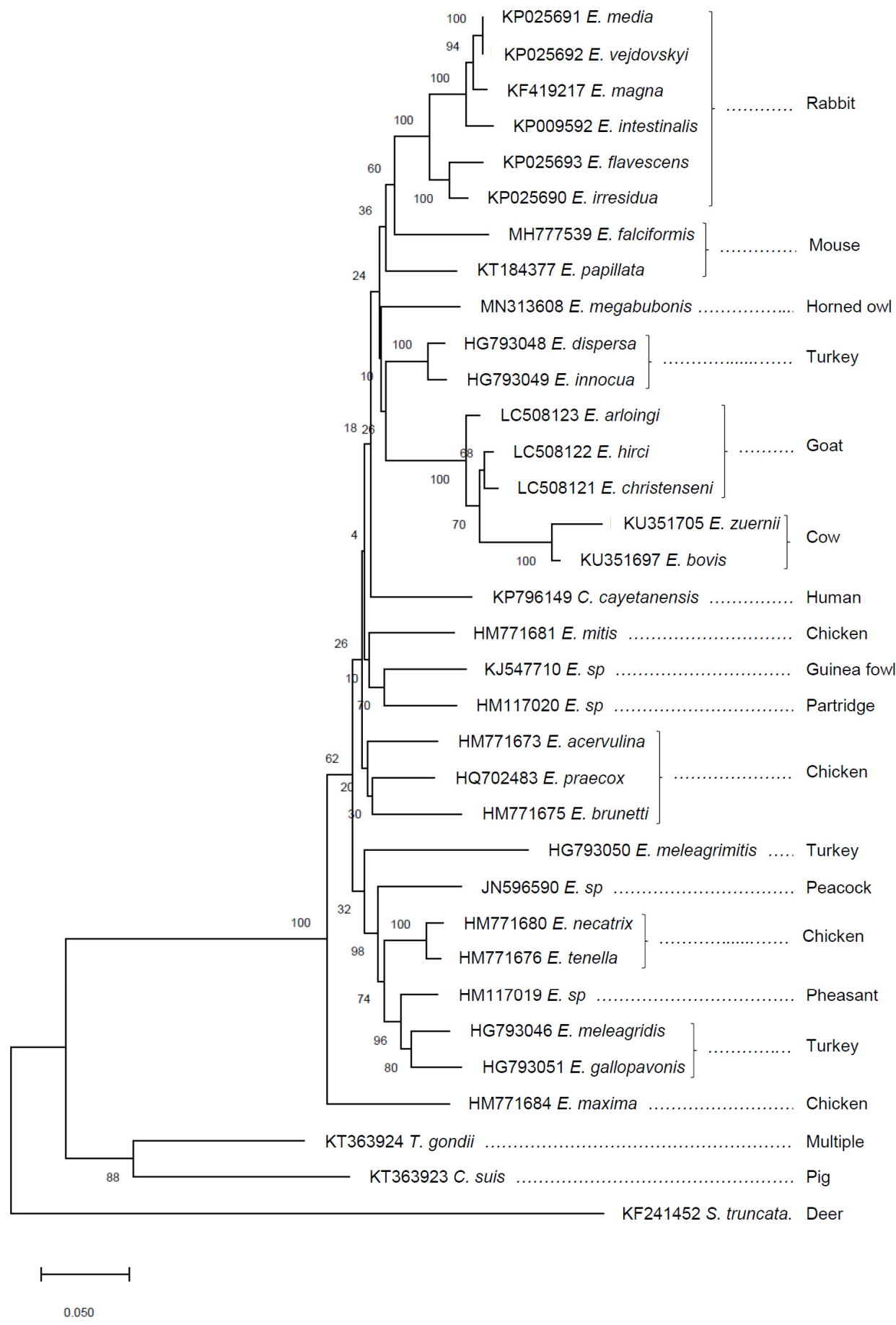

Figure 1. Neighbor joining phylogeny of partial coccidian mitochondrial cytochrome c oxidase subunit I (COI) sequences. The optimal tree is shown with the percentage of replicate trees in which the associated taxa clustered together in the bootstrap test (1000 replicates) indicated next to the branches. GenBank accession numbers are shown for each sequence, followed by the parasite species and host (common name) identity. Sequences were aligned using CLC Main Workbench (version 8.0.1), creating a 788 bp alignment. The phylogeny was inferred using MEGA X [56], with the evolutionary distances computed using the Kimura 2-parameter method.

In addition to Eimeria and Cyclospora, genome sequence assemblies have been published for five other coccidian genera/species: Cystoisospora suis (one strain available in ToxoDB), Hammondia hammondi (one), Neospora caninum (one), Sarcocystis neurona (two) and T. gondii (18), all within the family 
Sarcocystidae. Comparison of the Eimeria genomes with members of the Sarcocystidae suggest the absence of synteny, with different repeat occurrence and distributions [10]. This differs from the complete synteny that exists between the mitochondrial and apicoplast genomes of E. tenella and C. cayetanensis [50]. Microneme and rhoptry organelles are conserved between these genera, although the protein repertoires vary. For example, while many microneme proteins share some structural conservation between Eimeria and T. gondii, Eimeria genomes contain fewer rhoptry kinase (ropk) genes [10,57].

Significant opportunities exist for comparison between different Eimeria genomes. For example, genome sequencing from phylogenetically distinct species such as E. gruis and E. reichenowi from migratory crane [18] may inform on phenotypes associated with disseminated visceral coccidiosis, possibly revealing new genera. Similarly, accessing genomes of atypical Eimeria species such as E. leuckarti, E. macusaniensis, E. truncata and E. stiedai, from horses, alpacas, geese and rabbits, respectively [58-61], may offer insights into their unique biologies.

\section{Population Genetics}

Eimeria field populations are complex. At least seven species can infect chickens, frequently co-occurring in overlapping multi-species infections [62]. The outcome of infection is influenced by the host and the parasite. For example, individual commercial or inbred chickens have been shown to present varied levels of resistance, tolerance or susceptibility to infection by different Eimeria species and strains [63-65], creating significant polymorphism within and between flocks. Similarly, Eimeria strain-specific immunity has been described following infection with E. acervulina [66], E. mitis [67], E. maxima [63] or E. tenella [68], indicating the occurrence of strain-specific antigenic polymorphism and varied strain-specific immune selection during subsequent parasite infections. Other notable variables include farmed chicken population structures, where large numbers of chickens are commonly reared at high stocking densities over very short periods, encouraging rapid Eimeria cycling. Short parasite generation times provide opportunities for rapid evolutionary events, for example development of differing levels of fecundity or pathogenicity $[69,70]$. Signatures of selection within Eimeria populations of chickens are expected to be diverse, including purifying selection under the influence anticoccidial prophylaxis using drugs, or balancing selection imposed by immunity following natural infection. The use of live parasite anticoccidial vaccines may result in mixed signatures of selection, depending on the nature and diversity of local field populations.

Few population genetics studies have been published for Eimeria, in part due to the paucity of appropriate tools. Genome-wide genetic markers have been developed using tools such as Random Amplification of Polymorphic DNA-Polymerase Chain Reaction (RAPD-PCR) and Amplified Fragment Length Polymorphism (AFLP) (reviewed elsewhere [23]), but their utility with complex populations has been limited. Most genetics-led studies have focused on markers derived from the 18S-ITS1-5.8S-ITS2 rDNA repeat, located on chromosome 12 in the E. tenella genome [25,71], or markers such as COI in the mitochondrial genome [51]. Primarily used to assess Eimeria species occurrence (e.g., [72]), these marker sequences have also been used to define the occurrence of genetically distinct genotypes in different geographic locations or production systems, and to assess association with disease or performance outcomes [73]. In one of the most detailed studies, 248 ITS sequences were produced from Eimeria samples collected from 17 countries across Africa, Asia, Europe, North and South America [25]. Here, calculation of Wright's Fixation Index indicated allopatric diversity for E. tenella, but not E. acervulina or E. mitis, suggesting different population structures for different Eimeria species. Possible explanatory factors included the lower fecundity and longer prepatent period of the former species, providing a greater opportunity for genetic isolation. Another feature of the study was the detection of cryptic Eimeria OTU genotypes (named $\mathrm{x}, \mathrm{y}$ and $\mathrm{z}$ ), previously thought to be restricted to Australia, across much of the southern hemisphere [24,25], although the study was not able to identify their origin. Other locus specific approaches applied to Eimeria have included sequencing of multiple cloned PCR amplicons representing loci encoding the vaccine candidates Apical Membrane Antigen 1 
(AMA1) and Immune Mapped Protein 1 (IMP1). Targeted sequencing from E. tenella revealed low levels of nucleotide diversity with few non-synonymous substitutions and low levels of balancing selection [41,74]. Greater genetic distances were detected between parts of Asia and North Africa, although diversity remained low. Importantly, while these studies have been informative, single locus marker groups leave the majority of the nuclear and the apicoplast genomes unrepresented and risk bias in identification towards the most common genotype(s) in the sampled populations.

In 2015, a new, medium throughput tool was developed for E. tenella populations using Sequenom MassARRAY to genotype 55 single nucleotide polymorphisms (SNPs) in two multiplexes [41]. The SNPs were spread across the E. tenella karyotype to permit assessment of segregation and recombination, as well as diversity. Using E. tenella samples from India, Egypt, Libya and Nigeria, 52 of the SNPs were found to be informative. Analysis of the SNP profiles indicated considerable genome-wide genetic diversity with significant evidence of allopatric evolution. Detection of significant linkage disequilibrium (LD) in North Africa and northern India, but not Nigeria and southern India, suggested different population structures. Subsequent studies suggested contributions from climate and parasite prevalence led to the differences observed in LD, although further study is required [75]. The Sequenom MassARRAY SNP panel was also used to demonstrate that polyclonal infection was common in field populations, and that cross-fertilization occurs at a high frequency during co-infection [41]. Recognizing that Sequenom MassARRAY SNP typing is difficult to develop for routine application in regional laboratories, a subset of 11 SNPs used in the panel were redeveloped as PCR-Restriction Fragment Length Polymorphism (PCR-RFLP) genetic markers [76]. Application of the PCR-RFLP panel to new E. tenella samples collected in the United Kingdom and Ireland revealed a tightly restricted haplotype structure that was distinct from haplotypes detected previously in Africa and Asia.

Next generation sequencing (NGS) technologies have supported the development of new approaches to define population structures for a range of micro-organisms. Deep sequencing of PCR amplicons produced using generic or specific primer pairs has been used widely to define the presence/absence ( $\alpha$ diversity) and level of occurrence ( $\beta$ diversity) of bacterial populations [77]. The same approach has been developed to define parasite populations for nematodes, termed the 'nemabiome' [78], and Theileria parva [79]. Three groups have published studies of next generation deep amplicon sequencing for whole Eimeria populations. Amplicon sequencing of $18 \mathrm{~S}$ rDNA was first applied to communities of Eimeria from the Australian brush-tailed rock-wallaby [80]. A subsequent study involving Eimeria from chickens also focused on the $18 \mathrm{~S}$ rDNA, using Illumina MiSeq NGS to sequence amplicons produced from commercial and indigenous chickens sampled in India [81]. Sequence analysis provided a sensitive assessment of Eimeria species occurrence, validated by standard and quantitative species-specific PCR, and successfully detected the cryptic Eimeria genotypes OTUs $x$ and $y$ as well as a range of other related protozoan pathogens. However, detection of low levels of DNA representing other Eimeria species not classically associated with chickens did appear to indicate some background noise. Annotation of sequences assigned previously to Eimeria infecting rock partridges (Alectoris graeca) and wild turkeys (Meleagris gallopavo) may have represented farm-level contamination with non-replicating Eimeria oocysts or DNA, or false positives [81]. These latter results indicate a requirement for additional validation and/or more specific primers. The second poultry study also targeted the Eimeria 18S rDNA, supplemented by COI, but followed a nested PCR approach using inner and outer primers, followed by MiniSeq NGS, in an attempt to increase specificity and sensitivity [27]. Application of the nested $18 \mathrm{~S}$ and COI NGS assays to live anticoccidial vaccines and field samples collected from backyard and commercial chickens revealed best results for the $18 \mathrm{~S}$ rDNA, confirmed by quantitative TaqMan PCR. Analysis of the $18 \mathrm{~S}$ rDNA and COI datasets identified the presence of the cryptic Eimeria OTUs x, y and z in North America for the first time [27]. However, as for the publication by Hinsu et al. [81], a series of additional sequences associated with non-chicken hosts were also detected including ferrets, rodents and rock partridge. Furthermore, novel sequences lacking a matching annotated reference sequence were also detected. Considered by the authors to represent up to nine new Eimeria OTUs (labelled 1-4 and A-E), further validation is required to confirm that these 
sequences do not simply represent environmental contamination with non-replicating Eimeria oocysts or DNA from other sources, especially given the use of backyard chickens for most of the samples. Combined, these studies demonstrate the value of NGS amplicon sequencing to studies of Eimeria populations, but highlight the requirement for optimal primer design and quality control. As Eimeria genome sequence assemblies improve, population profiling through whole genome metagenomics may become feasible. Metagenomic approaches for population profiling have been applied to bacterial populations for several years [82], but have not yet become common for parasite communities due in part to expense, given the far greater cost of sequencing larger parasite genomes at an appropriate depth. The fragmented nature of many parasite genomes has also been limiting.

\section{Challenges}

It is now more than 100 years since the significance of coccidiosis was first recognized in poultry $[83,84]$, but many notable gaps persist in our knowledge. We are farming more poultry than ever before, with a greater reliance on poultry meat and eggs for provision of dietary protein for human consumption [85]. Concurrently, we are attempting to reduce routine reliance on relatively indiscriminate, genus-wide, anticoccidial drugs, replacing them with precise species- and sometimes strain-specific vaccines. The appearance of cryptic Eimeria genotypes is problematic. While these genotypes are likely to be controlled by anticoccidial drugs to the same extent as the recognized species, they may be capable of escape from commercial anticoccidial vaccines [86]. Understanding genetic diversity, population structure and capacity to evolve has never been more important for control of Eimeria species parasites. Key questions surround the ability of Eimeria to evolve to escape current live or future subunit vaccines. The nature of eimerian genome evolution is poorly defined, including rates of cross-fertilization in field populations and the occurrence of genetic recombination. Indeed, the possibility of viable hybridization between Eimeria species, as has been described for other apicomplexans (e.g., Plasmodium berghei and P. yoelii [87]), remains unclear. Developing new, high throughput genome-wide genetic markers beyond the current ribosomal and mitochondrial options will be important to understand how Eimeria populations behave under deleterious drug or vaccine selection, and to better explore host-parasite cospeciation [54].

\section{Opportunities}

The ongoing revolution in next- and third-generation sequencing technologies offers good prospects for studies with veterinary pathogens. Costs associated with DNA extraction, library preparation and sequencing are falling fast. Other restraints including stringent requirements for high nucleic acid template quality and quantity, previously limiting for organisms that cannot be cultured in vitro, are relaxing. Routine laboratory or even field sequencing using platforms such as Oxford Nanopore is now improving accessibility to genomic sciences. For Eimeria, applications to genomes, comparative genomics and population genetics can be numerous. Long read sequencing can be used to improve the current draft genome sequence assemblies, confirm karyotype numbers and access spatially, temporally and phenotypically distinct isolates. Work can expand to include more Eimeria species, including those from other livestock and wild animal populations, to explore synteny and ancestral associations. In time, sequencing may be applied to routine diagnostics, differentiating vaccine strains from field isolates and informing selection of optimal chemoprophylactic programmes. In the short term, identification of improved primers for NGS deep amplicon sequencing from Eimeria populations and strategies to control for the influence of background/non-target DNA is likely to prompt a much wider uptake of routine sequencing studies.

\section{Conclusions}

As methods to control Eimeria are evolving so are the tools we use to investigate them. Detection of unexpected genome- and population-level complexities has renewed interest in study of these parasites that can support improved controls and safeguard the sustainability of livestock production. 
Author Contributions: D.P.B., K.W. and M.C.J. drafted and reviewed the manuscript. All authors have read and agreed to the published version of the manuscript.

Funding: Much of the work described here was supported by the Biotechnology and Biological Sciences Research Council (BBSRC) under grants including BB/L00478X/1 and BB/H009337/1, and the USDA-Agricultural Research Service under Project No. 8042-32000-111-00D. This research was also supported in part by KW's appointment to the Agricultural Research Participation Program administered by the Oak Ridge Institute for Science and Education (ORISE) through an interagency agreement between the U.S. Department of Energy (DOE) and the U.S. Department of Agriculture (USDA). ORISE is managed by ORAU and DOE under contract number DE-SC0014664.

Acknowledgments: The Royal Veterinary College has assigned this manuscript the reference number PPS_02245.

Conflicts of Interest: The authors declare no conflict of interest. The sponsors had no role in the design, execution, interpretation, or writing of the study.

\section{References}

1. Dubey, J.P. Coccidiosis in Livestock, Poultry, Companion Animals, and Humans; CRC Press, Taylor \& Francis Group: Boca Raton, FL, USA, 2020.

2. Vrba, V.; Pakandl, M. Host specificity of turkey and chicken Eimeria: Controlled cross-transmission studies and a phylogenetic view. Vet. Parasitol. 2015, 208, 118-124. [CrossRef] [PubMed]

3. Wiedmer, S.; Erdbeer, A.; Volke, B.; Randel, S.; Kapplusch, F.; Hanig, S.; Kurth, M. Identification and analysis of Eimeria nieschulzi gametocyte genes reveal splicing events of gam genes and conserved motifs in the wall-forming proteins within the genus Eimeria (coccidia, apicomplexa). Parasite 2017, 24, 50. [CrossRef] [PubMed]

4. Morrissette, N.S.; Sibley, L.D. Cytoskeleton of apicomplexan parasites. Microbiol. Mol. Biol. Rev. 2002, 66, 21-38. [CrossRef] [PubMed]

5. Blake, D.; Knox, J.; Dehaeck, B.; Huntington, B.; Rathinam, T.; Ravipati, V.; Ayoade, S.; Gilbert, W.; Adebambo, A.; Jatau, I.; et al. Re-Calculating the cost of coccidiosis in chickens. Vet. Res. 2020, 51, 115. [CrossRef] [PubMed]

6. Chapman, H.D.; Jeffers, T.K. Vaccination of chickens against coccidiosis ameliorates drug resistance in commercial poultry production. Int. J. Parasitol. Drugs Drug Resist. 2014, 4, 214-217. [CrossRef] [PubMed]

7. USAHA. Report of the USAHA Committee on Poultry and Other Avian Species. United States Animal Health Association: 2019. Available online: https://www.Usaha.Org/transmissible-diseases-of-poultryavian-species (accessed on 12 June 2020).

8. FAOSTAT. Food and Agriculture Organization of the United Nations Faostat Database. Available online: http://faostat3.fao.org/home/E (accessed on 19 May 2020).

9. Lopez-Osorio, S.; Silva, L.M.R.; Chaparro-Gutierrez, J.J.; Velasquez, Z.D.; Taubert, A.; Hermosilla, C. Optimized excystation protocol for ruminant Eimeria bovis- and Eimeria arloingi-sporulated oocysts and first 3d holotomographic microscopy analysis of differing sporozoite egress. Parasitol. Int. 2020, 76, 102068. [CrossRef]

10. Reid, A.J.; Blake, D.P.; Ansari, H.R.; Billington, K.; Browne, H.P.; Bryant, J.; Dunn, M.; Hung, S.S.; Kawahara, F.; Miranda-Saavedra, D. Genomic analysis of the causative agents of coccidiosis in domestic chickens. Genome Res. 2014, 24, 1676-1685. [CrossRef]

11. Blake, D.P.; Billington, K.J.; Copestake, S.L.; Oakes, R.D.; Quail, M.A.; Wan, K.L.; Shirley, M.W.; Smith, A.L. Genetic mapping identifies novel highly protective antigens for an apicomplexan parasite. PLoS Pathog. 2011, 7, e1001279. [CrossRef]

12. Shirley, M.W.; Harvey, D.A. Eimeria tenella: Infection with a single sporocyst gives a clonal population. Parasitology 1996, 112, 523-528. [CrossRef]

13. Williams, R.B. Epidemiological studies of coccidiosis in the domesticated fowl (gallus gallus): II. Physical condition and survival of Eimeria acervulina oocysts in poultry-house litter. Appl. Parasitol. 1995, 36, 90-96.

14. Jenkins, M.C.; Parker, C.C.; O'Brien, C.N.; Ritter, D. Viable Eimeria oocysts in poultry house litter at the time of chick placement. Poult. Sci. 2019, 98, 3176-3180. [CrossRef] [PubMed]

15. Long, P.; Joyner, L.; Millard, B.; Norton, C. A guide to laboratory techniques used in the study and diagnosis of avian coccidiosis. Folia Vet. Lat. 1976, 6, 201-217. [PubMed] 
16. Jeanes, C.; Vaughan-Higgins, R.; Green, R.E.; Sainsbury, A.W.; Marshall, R.N.; Blake, D.P. Two new Eimeria species parasitic in corncrakes (Crex crex) (gruiformes: Rallidae) in the United Kingdom. J. Parasitol. 2013, 99, 634-638. [CrossRef] [PubMed]

17. Novilla, M.N.; Carpenter, J.W.; Jeffers, T.K.; White, S.L. Pulmonary lesions in disseminated visceral coccidiosis of sandhill and whooping cranes. J. Wildl. Dis. 1989, 25, 527-533. [CrossRef]

18. Matsubayashi, M.; Takami, K.; Abe, N.; Kimata, I.; Tani, H.; Sasai, K.; Baba, E. Molecular characterization of crane coccidia, Eimeria gruis and E. reichenowi, found in feces of migratory cranes. Parasitol. Res. 2005, 97, 80-83. [CrossRef]

19. Liu, S.; Wang, L.; Zheng, H.; Xu, Z.; Roellig, D.M.; Li, N.; Frace, M.A.; Tang, K.; Arrowood, M.J.; Moss, D.M.; et al. Comparative genomics reveals Cyclospora cayetanensis possesses coccidia-like metabolism and invasion components but unique surface antigens. BMC Genom. 2016, 17, 316. [CrossRef]

20. Palmieri, N.; Shrestha, A.; Ruttkowski, B.; Beck, T.; Vogl, C.; Tomley, F.; Blake, D.P.; Joachim, A. The genome of the protozoan parasite Cystoisospora suis and a reverse vaccinology approach to identify vaccine candidates. Int. J. Parasitol. 2017, 47, 189-202. [CrossRef]

21. Vrba, V.; Poplstein, M.; Pakandl, M. The discovery of the two types of small subunit ribosomal RNA gene in Eimeria mitis contests the existence of E. mivati as an independent species. Vet. Parasitol. 2011, 183, 47-53. [CrossRef]

22. Ogedengbe, M.E.; El-Sherry, S.; Ogedengbe, J.D.; Chapman, H.D.; Barta, J.R. Phylogenies based on combined mitochondrial and nuclear sequences conflict with morphologically defined genera in the eimeriid coccidia (apicomplexa). Int. J. Parasitol. 2018, 48, 59-69. [CrossRef]

23. Beck, H.P.; Blake, D.; Darde, M.L.; Felger, I.; Pedraza-Diaz, S.; Regidor-Cerrillo, J.; Gomez-Bautista, M.; Ortega-Mora, L.M.; Putignani, L.; Shiels, B.; et al. Molecular approaches to diversity of populations of apicomplexan parasites. Int. J. Parasitol. 2009, 39, 175-189. [CrossRef]

24. Cantacessi, C.; Riddell, S.; Morris, G.M.; Doran, T.; Woods, W.G.; Otranto, D.; Gasser, R.B. Genetic characterization of three unique operational taxonomic units of Eimeria from chickens in Australia based on nuclear spacer ribosomal DNA. Vet. Parasitol. 2008, 152, 226-234. [CrossRef] [PubMed]

25. Clark, E.L.; Macdonald, S.E.; Thenmozhi, V.; Kundu, K.; Garg, R.; Kumar, S.; Ayoade, S.; Fornace, K.M.; Jatau, I.D.; Moftah, A.; et al. Cryptic Eimeria genotypes are common across the southern but not northern hemisphere. Int. J. Parasitol. 2016, 46, 537-544. [CrossRef] [PubMed]

26. Morgan, J.A.T.; Godwin, R.M. Mitochondrial genomes of australian chicken Eimeria support the presence of ten species with low genetic diversity among strains. Vet. Parasitol. 2017, 243, 58-66. [CrossRef] [PubMed]

27. Hauck, R.; Carrisosa, M.; McCrea, B.A.; Dormitorio, T.; Macklin, K.S. Evaluation of next-generation amplicon sequencing to identify Eimeria spp. of chickens. Avian Dis. 2019, 63, 577-583. [CrossRef] [PubMed]

28. Shirley, M. The genome of Eimeria tenella: Further studies on its molecular organisation. Parasitol. Res. 1994, 80, 366-373. [CrossRef] [PubMed]

29. Del Cacho, E.; Pages, M.; Gallego, M.; Monteagudo, L.; Sánchez-Acedo, C. Synaptonemal complex karyotype of Eimeria tenella. Int. J. Parasitol. 2005, 35, 1445-1451. [CrossRef]

30. Cai, X.; Fuller, A.L.; McDougald, L.R.; Zhu, G. Apicoplast genome of the coccidian Eimeria tenella. Gene 2003, 321, 39-46. [CrossRef]

31. Lee, S.; Fernando, M.A.; Nagy, E. dsRNA associated with virus-like particles in Eimeria spp. of the domestic fowl. Parasitol. Res. 1996, 82, 518-523. [CrossRef]

32. Wu, B.; Zhang, X.; Gong, P.; Li, M.; Ding, H.; Xin, C.; Zhao, N.; Li, J. Eimeria tenella: A novel dsRNA virus in E. tenella and its complete genome sequence analysis. Virus Genes 2016, 52, 244-252. [CrossRef]

33. Shirley, M.W.; Harvey, D.A. A genetic linkage map of the apicomplexan protozoan parasite Eimeria tenella. Genome Res. 2000, 10, 1587-1593. [CrossRef]

34. Del Cacho, E.; Gallego, M.; Monteagudo, L.; Lopez-Bernad, F.; Quilez, J.; Sanchez-Acedo, C. A method for the sequential study of eimerian chromosomes by light and electron microscopy. Vet. Parasitol. 2001, 94, 221-226. [CrossRef]

35. Xia, J.; Venkat, A.; Le Roch, K.; Ay, F.; Boyle, J. Third generation sequencing revises the molecular karyotype for Toxoplasma gondii and identifies emerging copy number variants in sexual recombinants. bioRxiv 2020. [CrossRef] 
36. Berna, L.; Marquez, P.; Cabrera, A.; Greif, G.; Francia, M.; Robello, C. Reevaluation of the Toxoplasma gondii and Neospora caninum genomes reveals misassembly, karyotype differences and chromosomal rearrangements. bioRxiv 2020. [CrossRef]

37. Ling, K.-H.; Rajandream, M.-A.; Rivailler, P.; Ivens, A.; Yap, S.-J.; Madeira, A.M.; Mungall, K.; Billington, K.; Yee, W.-Y.; Bankier, A.T. Sequencing and analysis of chromosome 1 of Eimeria tenella reveals a unique segmental organization. Genome Res. 2007, 17, 311-319. [CrossRef]

38. Heitlinger, E.; Spork, S.; Lucius, R.; Dieterich, C. The genome of Eimeria falciformis-Reduction and specialization in a single host apicomplexan parasite. BMC Genom. 2014, 15, 696. [CrossRef] [PubMed]

39. Blake, D.P.; Alias, H.; Billington, K.J.; Clark, E.L.; Mat-Isa, M.N.; Mohamad, A.F.; Mohd-Amin, M.R.; Tay, Y.L.; Smith, A.L.; Tomley, F.M.; et al. EmaxDB: Availability of a first draft genome sequence for the apicomplexan Eimeria maxima. Mol. Biochem. Parasitol. 2012, 184, 48-51. [CrossRef]

40. Gajria, B.; Bahl, A.; Brestelli, J.; Dommer, J.; Fischer, S.; Gao, X.; Heiges, M.; Iodice, J.; Kissinger, J.C.; Mackey, A.J.; et al. ToxoDB: An integrated Toxoplasma gondii database resource. Nucleic Acids Res. 2008, 36, D553-D556. [CrossRef]

41. Blake, D.P.; Clark, E.L.; Macdonald, S.E.; Thenmozhi, V.; Kundu, K.; Garg, R.; Jatau, I.D.; Ayoade, S.; Kawahara, F.; Moftah, A.; et al. Population, genetic, and antigenic diversity of the apicomplexan Eimeria tenella and their relevance to vaccine development. Proc. Natl. Acad. Sci. USA 2015, 112, e5343-e5350. [CrossRef]

42. Gopinath, G.R.; Cinar, H.N.; Murphy, H.R.; Durigan, M.; Almeria, M.; Tall, B.D.; DaSilva, A.J. A hybrid reference-guided de novo assembly approach for generating Cyclospora mitochondrion genomes. Gut Pathog. 2018, 10, 15. [CrossRef]

43. Jahn, D.; Matros, A.; Bakulina, A.Y.; Tiedemann, J.; Schubert, U.; Giersberg, M.; Haehnel, S.; Zoufal, K.; Mock, H.P.; Kipriyanov, S.M. Model structure of the immunodominant surface antigen of Eimeria tenella identified as a target for sporozoite-neutralizing monoclonal antibody. Parasitol. Res. 2009, 105, 655-668. [CrossRef]

44. Chow, Y.P.; Wan, K.L.; Blake, D.P.; Tomley, F.; Nathan, S. Immunogenic Eimeria tenella glycosylphosphatidylinositolanchored surface antigens (SAGS) induce inflammatory responses in avian macrophages. PLoS ONE 2011, 6, e25233. [CrossRef] [PubMed]

45. Denny, P.W.; Preiser, P.R.; Rangachari, K.; Roberts, K.; Roy, A.; Whyte, A.; Strath, M.; Moore, D.J.; Moore, P.W.; Williamson, D.H. Complete gene map of the plastid-like DNA of the malaria parasite Plasmodium falciparum. J. Mol. Biol. 1996, 261, 155-172.

46. Köhler, S.; Delwiche, C.F.; Denny, P.W.; Tilney, L.G.; Webster, P.; Wilson, R.; Palmer, J.D.; Roos, D.S. A plastid of probable green algal origin in apicomplexan parasites. Science 1997, 275, 1485-1489. [CrossRef] [PubMed]

47. Ramakrishnan, S.; Docampo, M.D.; MacRae, J.I.; Pujol, F.M.; Brooks, C.F.; Van Dooren, G.G.; Hiltunen, J.K.; Kastaniotis, A.J.; McConville, M.J.; Striepen, B. Apicoplast and endoplasmic reticulum cooperate in fatty acid biosynthesis in apicomplexan parasite Toxoplasma gondii. J. Biol. Chem. 2012, 287, 4957-4971. [CrossRef]

48. Van Dooren, G.G.; Striepen, B. The algal past and parasite present of the apicoplast. Annu. Rev. Microbiol. 2013, 67, 271-289. [CrossRef] [PubMed]

49. Van Dooren, G.G.; Kennedy, A.T.; McFadden, G.I. The use and abuse of heme in apicomplexan parasites. Antioxid. Redox Signal. 2012, 17, 634-656. [CrossRef]

50. Tang, K.; Guo, Y.; Zhang, L.; Rowe, L.A.; Roellig, D.M.; Frace, M.A.; Li, N.; Liu, S.; Feng, Y.; Xiao, L. Genetic similarities between Cyclospora cayetanensis and cecum-infecting avian Eimeria spp. in apicoplast and mitochondrial genomes. Parasites Vectors 2015, 8, 358. [CrossRef]

51. Ogedengbe, M.E.; El-Sherry, S.; Whale, J.; Barta, J.R. Complete mitochondrial genome sequences from five Eimeria species (apicomplexa; coccidia; eimeriidae) infecting domestic turkeys. Parasites Vectors 2014, 7, 335. [CrossRef]

52. Liu, G.H.; Tian, S.Q.; Cui, P.; Fang, S.F.; Wang, C.R.; Zhu, X.Q. The complete mitochondrial genomes of five Eimeria species infecting domestic rabbits. Exp. Parasitol. 2015, 159, 67-71. [CrossRef]

53. Mehlhorn, H. Coccidia. In Encyclopedia of Parasitology; Mehlhorn, H., Ed.; Springer: Berlin/Heidelberg, Germany, 2015.

54. Jarquin-Diaz, V.H.; Balard, A.; Macova, A.; Jost, J.; Roth von Szepesbela, T.; Berktold, K.; Tank, S.; Kvicerova, J.; Heitlinger, E. Generalist Eimeria species in rodents: Multilocus analyses indicate inadequate resolution of established markers. Ecol. Evol. 2020, 10, 1378-1389. [CrossRef] 
55. Norton, C.C.; Joyner, L.P. The appearance of bisporocytic oocysts of Eimeria maxima in drug-treated chicks. Parasitology 1978, 77, 243-248. [CrossRef] [PubMed]

56. Kumar, S.; Stecher, G.; Li, M.; Knyaz, C.; Tamura, K. Mega X: Molecular evolutionary genetics analysis across computing platforms. Mol. Biol. Evol. 2018, 35, 1547-1549. [CrossRef]

57. Carruthers, V.B.; Tomley, F.M. Microneme proteins in apicomplexans. Subcell. Biochem. 2008, 47, $33-45$. [PubMed]

58. Dubey, J.P.; Bauer, C. A review of Eimeria infections in horses and other equids. Vet. Parasitol. 2018, 256, 58-70. [CrossRef] [PubMed]

59. Dubey, J.P. A review of coccidiosis in south american camelids. Parasitol. Res. 2018, 117, 1999-2013. [CrossRef]

60. Jing, J.; Liu, C.; Zhu, S.X.; Jiang, Y.M.; Wu, L.C.; Song, H.Y.; Shao, Y.X. Pathological and ultrastructural observations and liver function analysis of Eimeria stiedai-infected rabbits. Vet. Parasitol. 2016, 223, 165-172. [CrossRef]

61. Gajadhar, A.A.; Stockdale, P.H.; Cawthorn, R.J. Ultrastructural studies of the zygote and oocyst wall formation of Eimeria truncata of the lesser snow goose. J. Protozool. 1986, 33, 341-344. [CrossRef]

62. Jatau, I.D.; Lawal, I.A.; Kwaga, J.K.; Tomley, F.M.; Blake, D.P.; Nok, A.J. Three operational taxonomic units of Eimeria are common in nigerian chickens and may undermine effective molecular diagnosis of coccidiosis. BMC Vet. Res. 2016, 12, 86. [CrossRef]

63. Smith, A.L.; Hesketh, P.; Archer, A.; Shirley, M.W. Antigenic diversity in Eimeria maxima and the influence of host genetics and immunization schedule on cross-protective immunity. Infect. Immun. 2002, 70, 2472-2479. [CrossRef]

64. Boulton, K.; Nolan, M.J.; Wu, Z.; Psifidi, A.; Riggio, V.; Harman, K.; Bishop, S.C.; Kaiser, P.; Abrahamsen, M.S.; Hawken, R.; et al. Phenotypic and genetic variation in the response of chickens to Eimeria tenella induced coccidiosis. Genet. Sel. Evol. 2018, 50, 63. [CrossRef]

65. Bumstead, N.; Millard, B. Variation in susceptibility of inbred lines of chickens to seven species of Eimeria. Parasitology 1992, 104, 407-413. [CrossRef] [PubMed]

66. Joyner, L.P. Immunological variation between two strains of Eimeria acervulina. Parasitology 1969, 59, 725-732. [CrossRef] [PubMed]

67. McDonald, V.; Shirley, M.W.; Chapman, H.D. Attenuation of Eimeria species: Further characterisation of two lines of Eimeria mitis. Res. Vet. Sci. 1985, 39, 328-332. [CrossRef]

68. Awad, A.M.; El-Nahas, A.F.; Abu-Akkada, S.S. Evaluation of the protective efficacy of the anticoccidial vaccine coccivac-b in broilers, when challenged with egyptian field isolates of E. tenella. Parasitol. Res. 2013, 112, 113-121. [CrossRef] [PubMed]

69. Abu-Akkada, S.S.; Awad, A.M. Isolation, propagation, identification and comparative pathogenicity of five Egyptian field strains of Eimeria tenella from broiler chickens in five different provinces in Egypt. Res. Vet. Sci. 2012, 92, 92-95. [CrossRef] [PubMed]

70. Williams, R.B.; Marshall, R.N.; Pages, M.; Dardi, M.; del Cacho, E. Pathogenesis of Eimeria praecox in chickens: Virulence of field strains compared with laboratory strains of e. Praecox and Eimeria acervulina. Avian Pathol. 2009, 38, 359-366. [CrossRef]

71. Shirley, M.W. The genome of Eimeria spp., with special reference to eimeria tenella-A coccidium from the chicken. Int. J. Parasitol. 2000, 30, 485-493. [CrossRef]

72. Kumar, S.; Garg, R.; Moftah, A.; Clark, E.L.; Macdonald, S.E.; Chaudhry, A.S.; Sparagano, O.; Banerjee, P.S.; Kundu, K.; Tomley, F.M.; et al. An optimised protocol for molecular identification of Eimeria from chickens. Vet. Parasitol. 2014, 199, 24-31. [CrossRef]

73. Schwarz, R.S.; Jenkins, M.C.; Klopp, S.; Miska, K.B. Genomic analysis of Eimeria spp. Populations in relation to performance levels of broiler chicken farms in arkansas and north carolina. J. Parasitol. 2009, 95, 871-880. [CrossRef]

74. Kundu, K.; Garg, R.; Kumar, S.; Mandal, M.; Tomley, F.M.; Blake, D.P.; Banerjee, P.S. Humoral and cytokine response elicited during immunisation with recombinant immune mapped protein-1 (etimp-1) and oocysts of Eimeria tenella. Vet. Parasitol. 2017, 244, 44-53. [CrossRef]

75. Chengat Prakashbabu, B.; Thenmozhi, V.; Limon, G.; Kundu, K.; Kumar, S.; Garg, R.; Clark, E.L.; Srinivasa Rao, A.S.; Raj, D.G.; Raman, M.; et al. Eimeria species occurrence varies between geographic regions and poultry production systems and may influence parasite genetic diversity. Vet. Parasitol. 2017, 233, 62-72. [CrossRef] [PubMed] 
76. Pegg, E.; Doyle, K.; Clark, E.L.; Jatau, I.D.; Tomley, F.M.; Blake, D.P. Application of a new PCR-RFLP panel suggests a restricted population structure for Eimeria tenella in UK and Irish chickens. Vet. Parasitol. 2016, 229, 60-67. [CrossRef] [PubMed]

77. Macdonald, S.E.; Nolan, M.J.; Harman, K.; Boulton, K.; Hume, D.A.; Tomley, F.M.; Stabler, R.A.; Blake, D.P. Effects of Eimeria tenella infection on chicken caecal microbiome diversity, exploring variation associated with severity of pathology. PLoS ONE 2017, 12, e0184890. [CrossRef] [PubMed]

78. Avramenko, R.W.; Redman, E.M.; Lewis, R.; Bichuette, M.A.; Palmeira, B.M.; Yazwinski, T.A.; Gilleard, J.S. The use of nemabiome metabarcoding to explore gastro-intestinal nematode species diversity and anthelmintic treatment effectiveness in beef calves. Int. J. Parasitol. 2017, 47, 893-902. [CrossRef] [PubMed]

79. Hemmink, J.D.; Weir, W.; MacHugh, N.D.; Graham, S.P.; Patel, E.; Paxton, E.; Shiels, B.; Toye, P.G.; Morrison, W.I.; Pelle, R. Limited genetic and antigenic diversity within parasite isolates used in a live vaccine against Theileria parva. Int. J. Parasitol. 2016, 46, 495-506. [CrossRef] [PubMed]

80. Vermeulen, E.T.; Lott, M.J.; Eldridge, M.D.; Power, M.L. Evaluation of next generation sequencing for the analysis of Eimeria communities in wildlife. J. Microbiol. Methods 2016, 124, 1-9. [CrossRef]

81. Hinsu, A.T.; Thakkar, J.R.; Koringa, P.G.; Vrba, V.; Jakhesara, S.J.; Psifidi, A.; Guitian, J.; Tomley, F.M.; Rank, D.N.; Raman, M.; et al. Illumina next generation sequencing for the analysis of Eimeria populations in commercial broilers and indigenous chickens. Front. Vet. Sci. 2018, 5, 176. [CrossRef] [PubMed]

82. Padmanabhan, R.; Mishra, A.K.; Raoult, D.; Fournier, P.E. Genomics and metagenomics in medical microbiology. J. Microbiol. Methods 2013, 95, 415-424. [CrossRef]

83. Tyzzer, E. Coccidiosis in gallinaceous birds. Am. J. Hyg. 1929, 10, 269-383. [CrossRef]

84. Beach, J.; Corl, J. Studies in the control of avian coccidiosis. Poultry Sci. 1925, 4, 83-93. [CrossRef]

85. Gilbert, M.; Conchedda, G.; Van Boeckel, T.P.; Cinardi, G.; Linard, C.; Nicolas, G.; Thanapongtharm, W.; D'Aietti, L.; Wint, W.; Newman, S.H.; et al. Income disparities and the global distribution of intensively farmed chicken and pigs. PLoS ONE 2015, 10, e0133381. [CrossRef] [PubMed]

86. Morris, G.M.; Woods, W.G.; Richards, D.G.; Gasser, R.B. Investigating a persistent coccidiosis problem on a commercial broiler-breeder farm utilising PCR-coupled capillary electrophoresis. Parasitol. Res. 2007, 101, 583-589. [CrossRef] [PubMed]

87. Ramiro, R.S.; Khan, S.M.; Franke-Fayard, B.; Janse, C.J.; Obbard, D.J.; Reece, S.E. Hybridization and pre-zygotic reproductive barriers in Plasmodium. Proc. Biol. Sci. 2015, 282, 20143027. [CrossRef] [PubMed]

(C) 2020 by the authors. Licensee MDPI, Basel, Switzerland. This article is an open access article distributed under the terms and conditions of the Creative Commons Attribution (CC BY) license (http://creativecommons.org/licenses/by/4.0/). 